\title{
A Smart System to Ease Occurrence of Bedsores
}

\author{
B. Kommey, R. Agbozo, and G. E. Graham \\ Department of Computer Engineering, Kwame Nkrumah University of Science and Technology, KNUST - Kumasi, 00233 Ghana \\ Corresponding author: B. Kommey (e-mail: bkommey.coe@knust.edu.gh).
}

\begin{abstract}
The occurrence of bedsores in Ghanaian hospitals, elderly homes or care homes is especially high among patients or people who are incapacitated and cannot move or turn on their own, and who happen to remain in a particular posture for a very long time. Patients in coma, those operated on and for that matter in critical state, and patients confined to wheelchairs are primary examples. Constant pressure on some parts of the body leads to the occurrence of pressure sores or ulcers. This paper seeks to implement a Bedsore Easing System (BeSoSys) that integrate several embedded hardware components, a database and software to reduce the occurrence of bedsores. These embedded hardware components include the Bed Device Unit (BDU), the Pocket Device Unit (PDU), a pressure or weight sensor, a temperature sensor, and an inflation-deflation device. The BDU is fitted into the bed of the patient or on the surface of skin contact of the patient. The PDU is assigned to nurses or caretakers to serve as an alarm system for patient repositioning depending on situation. All activities in the Bedsore Easing System are logged into a database for future references. A bedridden patient exerts constant pressure on the bony protrusions of the body, and this causes bedsores. It was found out during the research that in Ghana, the nurses or caretakers used to turn and massage patients at some random time intervals as a way of preventing bedsores. This traditional way of turning and massaging patients is not only tedious but also ineffective. This paper seeks to provide easy, better, and effective solution to ease bedsores. The BeSoSys intends to prevent the occurrence of bedsores hence the alleviation of bedsore complications
\end{abstract}

INDEX TERMS Alert, Bedsore, Database, Pocket Device, Pressure Sensing, Temperature Sensing.

\section{INTRODUCTION}

Ghana is a developing country with massive growth in the health sector. With the current growth in health care, more people are being drawn to hospitals for treatment and admission. [1] addressed the health sector in relation to bedsores in Ghana. Also, there is an increase in senior citizens who are in one way or the other incapacitated and hence have difficulty in self-repositioning. These senior citizens, together with coma patients, chronically ill patients, accident victims, etc., are at high risk of acquiring a condition known as bedsores or decubitus ulcer.

In Ghana hospitals, the ratio of nurses to patients is encouraging, but still not good enough for nurses to pay undivided attention on each patient. Bedridden patients need frequent turns if bedsores are to be prevented. Nurses may do random check-ins, but since they are human, they are not perfect machines. Humans unlike machines, may not be able to attend to all patients equally, hence the many occurrences of bedsores in the hospitals. The inability to attend to bedsore patients may be partly due to parallel responsibilities of nurses or caretakers elsewhere within the hospital. Patients are getting bedsores in hospitals, and this condition may cause the patient to stay longer in the hospital even when the illness which brought them to the hospital has been treated successfully. Bedsore patients are open to more complications such as infections, cellulitis, osteomyelitis, and many more. The economy of Ghana and the health sector cannot support all these patients who need accommodation or admission in the hospitals. Hospitals cannot allow older patients to remain on admission due to conditions that could have been prevented. The Bedsore Easing System intends to mitigate the situation by helping to prevent the occurrence of bedsores, which could lead to a fast discharge of patients to make available rooms free for new or incoming patients. 
This paper seeks to help ease the occuence of bedsore with monitoring, logging and alert system called Bed Sore Easing System (BeSoSys). BeSoSys relies on the use of sensors (pressure and temperature), deflation device, and wireless technology for communicating and alerting.

\section{RELATED WORKS}

Bedsore is a condition that has plagued the health sector for many years. The desire to rid the health sector of this condition has caused many to attempt solutions aimed at preventing or reducing the occurrence of bedsores. This section of the paper, study the related works, and how they attempted to solve bedsore issues.

[2] proposed a mobile app implementation of a Clinical Decision Support System (CDSS). This solution was to help field operators to determine the bedsore and classify the stage, and all this was done using augmented reality and deep learning. Caretakers can make better decisions in the line of treatment not prevention. [3] proposed an IoT-based system that monitors patients based on body temperature, skin humidity and body immobility duration. Incorporated in the system was a mobile application to remotely monitor patient state. [4] introduced the use of a smart air mattress to control the occurrence of bedsores. This mattress uses pressure data and inflates and deflates to redistribute pressure along a patient's body whiles relieving pain.

Some other works are the 'Mattress for Preventing Bed Sores' [5], 'Patient Under sheet for preventing bed sores' [6], 'Fluid-Type Support Structure for Simulating FlotationType Support'[7], 'Monitoring System for Pressure Sore Prevention'[8], 'A flexible pressure monitoring system for pressure ulcer prevention' [9], 'Stage Identification Using Electromagnetic Waves for Noncontact Bed Sores Detection System' [10], 'Pressure ulcer condition sensing and monitoring'[11], 'Blanching response pressure sore detector apparatus and method' [12], 'Smart bed' [13], 'Adaptable surface for use in beds and chairs to reduce occurrence of pressure ulcers' [14], 'A cot to prevent and treat bedsores'

\section{MATERIAL AND METHOD}

\section{BeSoSys proposed system architecture}

Figure 1 depicts the proposed system architecture of the Bedsore Easing System (BeSoSys). The system has 3 main essential blocks: the Bed Device Unit (BDU) (figure 4), the Pocket Device Unit (PDU) (figure 5) and the Database Information Logging (DIL).

The BDU has a bed pad which is embedded with sensors; temperature and pressure sensors to be precise, and an inflation-deflation system. The display shows the pressure and temperature readings of the sensors. In the display is a wi-fi equipped microcontroller that processes all parameters
[15], 'Development of a new Bed System with Improved Decubitus Prophylaxis for Bed-Ridden Patients'[16], 'Automatic patient turner' [17], 'Cushion for decubitus ulcers' [18], and 'Bed' [19].

[20] and [21] proposed similar solutions - with a few improvements on how to curb pressure sores using Internet of Things (IoT). In this method, temperature sensors were employed and implanted onto the surface of the bed to take temperature readings and transmit to a microcontroller to determine the change in temperature of the patient's skin and bed. In later improvements, in addition to the temperature sensors, an inflatable pressure pad was implanted on the bed and interfaced with a microcontroller. This pad inflated and deflated based on temperature readings. An alarm system is also present to alert nurses or caretakers when temperature breaches a set threshold.

The implementation proposed by [22] was the use of a morphable tile bed that can shift itself or change form to redistribute pressure along the body of a patient. The authors used a combination of sensor networks, machine intelligence, computer control, a morphable, and tiled bed surface to help prevent the development of decubitus ulcers. Its advantages notwithstanding, this smart bed has no alert system to inform nurse or caretaker of ongoing changes hence may not be so dependable. Also, the smart bed is quite expensive and may not be deployable on a large scale in our hospitals. A recent work by [23] involved the use of 3D sensors and a computerized monitoring system to determine whether a patient has moved or been sufficiently moved to prevent patient bedsores. When a patient hasn't been moved in a certain amount of time, an alert is triggered. Despite all that, the system is costly and heavily dependent on the use of live video streaming from 3D sensors which will be a burden on power consumption. Also, with the current system, movement by others in the view or vicinity of the sensors may be seen as movement of the patient hence no alerts will be triggered.

that it receives. With a patient positioned on the bed, the pressure and temperature sensors take their readings. These parameters are transmitted after processing from the microcontroller to the display unit. The microcontroller checks the parameters and if a parameter value exceeds a set threshold, an alert is sent to the PDU with a nurse or caretaker. The alert can only be disabled from the display unit to prevent the nurse or caretaker from disabling same at their end without attending to the patient. The PDU upon receiving the alert displays the bed number on its screen to enable the nurse or caretaker to locate the patient. The alert comes with a buzz or vibration to signal the nurse or caretaker. In a hospital setting, the PDU is positioned on a couple of nurses. If an alert is sent to a PDU, after time $\mathbf{X}$, if 
the alert is not disabled, the alert is sent to a different nurse and the process continues. At the same time of the alert signal transmission, the inflation- deflation system is activated. It inflates and deflates to help redistribute pressure. To make sure nurses or caretakers act responsibly, the DIL logs all alerts and responses that has been received and saves same into the cloud. The database is accessed via a user interface software by the hospital or home management.

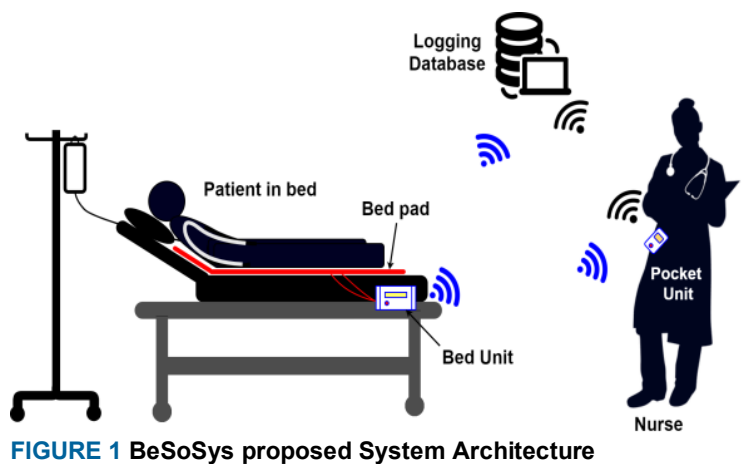

\section{BeSoSys System Communication and Sensing}

The three main units of the BeSoSys (BDU, PDU and DIL) intercommunicate via Wi-fi technology. BeSoSys is equipped with a microcontroller and has the sensors for gathering data from the BDU and the PDU. In the DIL, all data and information exchanged are logged to the database into the cloud.

The temperature and pressure or load sensors incorporated into the system are used to gather data that will be processed by another microcontroller embedded in the BDU. The processed data will be used in the triggering of alerts and the inflation and deflation system. Temperature build-up is proportional to the amount of time spent in contact with a surface, so when a body's skin remains for a while in close contact with a bed surface, heat begins to build up on that body part, and this rise in heat is monitored and used in the diagnosis of a possible occurrence of bedsores. The more the heat, the more the body part is prone to bedsores. The temperature sensors measure the temperature rise of the skin and send all data to the microcontroller of the BDU. Pressure is related to the formation of bedsores. Pressure is influenced by the force exerted by a body, and the area of contact with the surface.

$$
\boldsymbol{P}=\boldsymbol{F} / \boldsymbol{A} \text {. }
$$

where $\mathrm{P}$ indicated pressure in Newton $/ \mathrm{m}^{2}, \mathrm{~F}$ showed force in Newton, and A indicate area in $\mathrm{m}^{2}$

The smaller the area of the body or skin that contacts the bed, the higher the pressure; this accounts for why bedsores are prevalent on the bony protrusions of the body. The force is directly proportional to the pressure, hence the larger the force the higher the pressure exerted. The force is related to the mass of a body by

$$
f=\boldsymbol{m} x \boldsymbol{a}
$$

where $\mathrm{f}$ is force, $\mathrm{m}$ is mass in $\mathrm{kg}$ and $\mathrm{a}$ is accelartion in $\mathrm{m} / \mathrm{s}^{2}$. Hence different masses give different forces and exert different pressure. All set thresholds will be based on a particular range of mass. The pressure or load cell sensor used, as shown in figure 2 converts the pressure or compression into an electrical output that will be processed by the microcontroller. When a body presses on the load cell sensor, the force exerted by the body causes the strain gauge in the sensor to be deformed. That deformation is measured as a change in electrical signals. And these electrical signals are transferred to the microcontroller for processing.

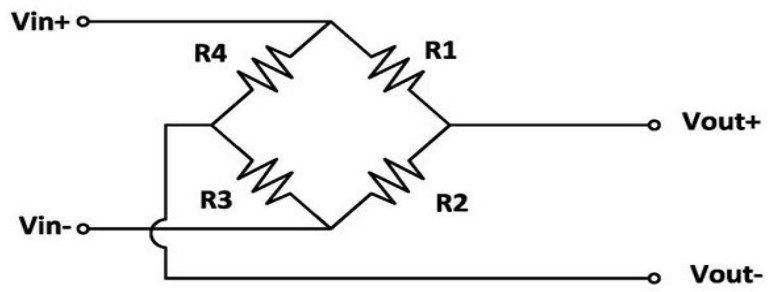

FIGURE 2 Circuit representation of the load cell

\section{BeSoSys Hardware Components}

Table I shows the various hardware components and descriptions of their functions as used in the project design.

TABLE I:

\begin{tabular}{|c|c|}
\hline COMPONENT & FEUNCTION \\
\hline$A T X M E G A 256 A 3-A U$ & High performance, low power 8bit uC. RISC \\
\hline$u C$ chip & $\begin{array}{l}256 \mathrm{~KB} \text { Flash, operating voltage ranges from } \\
1.8 \text { to } 3.3 \mathrm{~V} .64 \text {-pins }\end{array}$ \\
\hline $\begin{array}{l}\text { WIRELESS WI-FI } \\
\text { ESP-01 }\end{array}$ & $\begin{array}{l}\text { The wi-fi module for communication between } \\
\text { the BDU and the PDU, and for logging data } \\
\text { into the database of the hospital management } \\
\text { software }\end{array}$ \\
\hline Push Buttons & $\begin{array}{l}\text { A push power button on the BDU and PDU, to } \\
\text { control the ON/OFF states of the devices. A } \\
\text { reset push button directly on the uC to set the } \\
\text { chip to programming mode. And an 'alert } \\
\text { disable' push button to turn off the alert as } \\
\text { well as stop the air pump }\end{array}$ \\
\hline$U S B-A B M I C R O$ & $\begin{array}{l}\text { Code upload unto the chip via a serial USB } \\
\text { port/connection }\end{array}$ \\
\hline $\begin{array}{l}\text { CMOS cell battery } \\
\text { holder }\end{array}$ & $\begin{array}{l}\text { The pocket device is powered by CMOS } \\
\text { batteries and has a battery pack (holder) for } \\
\text { keeping the batteries on the board }\end{array}$ \\
\hline Power Outlet & $\begin{array}{l}\text { The power supply for the bed system is the } \\
\text { mains. A voltage regulator is used to control } \\
\text { the amount of power reaching the } \\
\text { microcontroller from the socket. A two-pin } \\
\text { adaptor is used here }\end{array}$ \\
\hline
\end{tabular}

BeSoSys HARDWARE COMPONENTS

Journal homepage: jeeemi.org 
LEDs

$16 \times 2$ LCD Screen

Air pump

Relay

Temperature Sensor

Pressure Sensor
The RGB LED is used on the PDU to serve as an indication of the battery level of the device, and the ON/OFF status of the device. Two red LEDs are used on the BDU. One for ON/OFF status, and the other as the alert trigger status The clock circuit determines the operating speed of the microcontroller. It is that which will tell the microcontroller how many instructions per second to execute. Use for synchronization

The LCD screen has two rows and sixteen columns for displaying the readings of the various sensors

Air pump used will fill the pad with air when triggered to do so. The air pump is small and sucks air from the environment through the inlet and releases it into the mattress through the outlet to inflate it

The relay is used here for the control of the air pump. The relay controls the switching of the air pump by closing and opening the contacts The body temperature of the patient is measured by the temperature sensor, and the values are sent to the microcontroller for processing. About 4 temperature sensors are placed at ideal spots to measure temperature in those areas

The pressure sensors are used to measure the pressure exerted by a part of the body at any given point in time. This is to accurately determine and monitor the build-up in pressure in the bedsore prone areas

A buzzer is used in the PDU to serve as an auditory alert to the nurse or caretakers

\section{Bed Device Unit (BDU)}

The BDU is made up of a Wi-Fi-equipped microcontroller, temperature and pressure sensors, an inflation-deflation pump, an LCD, LED, buttons, power source and a voltage regulator, among other things as shown in the diagram in figure 4.

The system is powered on with the power button, and an LED turns on to indicate the ON status. Once a patient is placed on the bed, the sensors take the readings and send them to the microcontroller for processing. These readings are displayed on the LCD. The microcontroller processes these readings and compares them to the set threshold, if it exceeds the threshold, an alert is sent to the PDU to notify the nurse or caretaker. There is an 'alert disable' button on the BDU that can cause the alert to be disengaged.

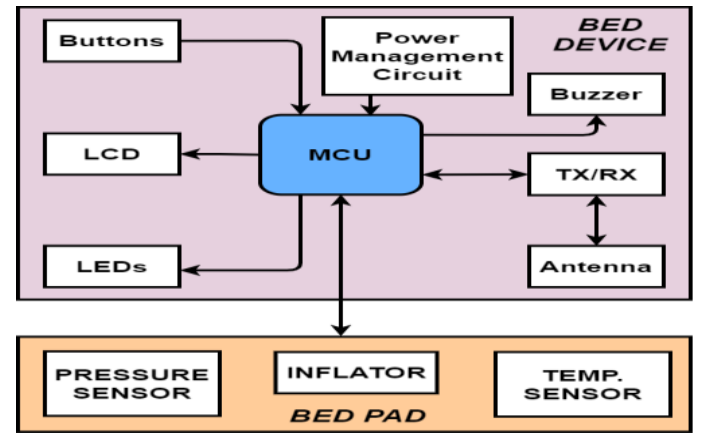

FIGURE 4 BDU Block Diagram

\section{BDU Workflow}

Figure 5 depicts the flow chart of the BDU. When the system is powered on at the start, there is continuous reading of temperature and pressure of the patient lying on the bed. When these readings are taken, they are displayed on the LCD screen. As this is happening, there is a conditional check on the temperature and pressure readings, if a reading exceeds a set threshold, the inflator system on the bed of the patient is activated to relieve the pressure on the patient. At the same time, a wireless signal is sent to the PDU to trigger an alarm for the nurse or caretaker's attention. As the signal is being transmitted to the PDU, there is another conditional check being made. If the 'alert disable' button on the bed system is not push, the system will keep sending signals to various PDUs for a specific amount of time. But once the 'alert disable' button is pressed, the inflator system is deactivated and no alert is further sent and the cycle ends and again restarted. The flow is repeated continuously till the whole system is powered down or turned off.

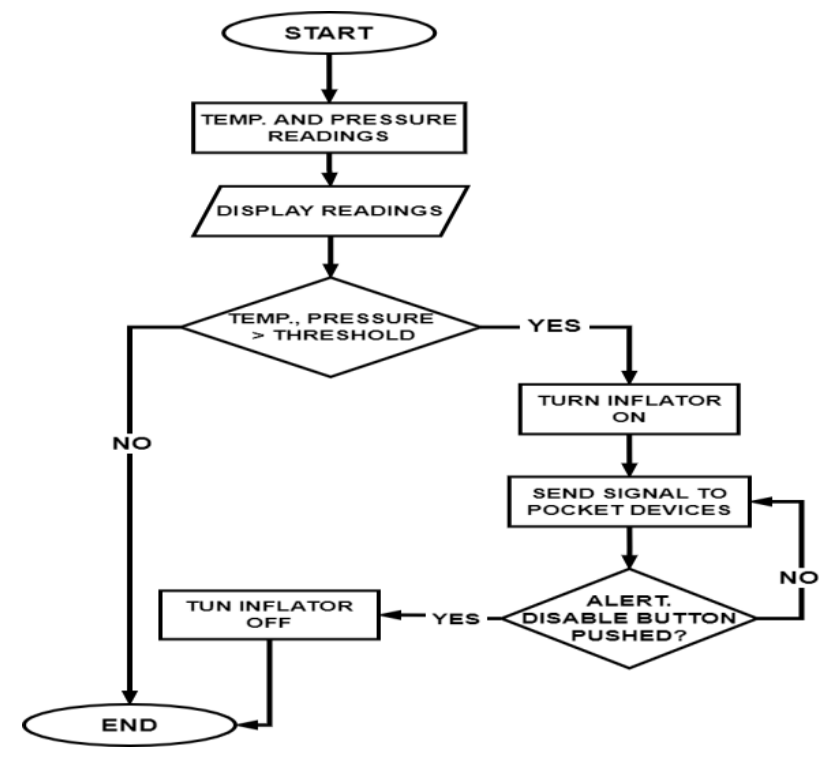

FIGURE 5 BDU Flow Chart

\section{Pocket Device Unit (PDU)}

The PDU is made up of a Wi-fi-equipped microcontroller, a CMOS battery, button, LED, buzzer, and LCD as shown in the block diagram in figure 6 . This mobile device which will be with the nurse or caretaker will receive a wireless signal from the BDU once it has been powered on and an alert has been triggered. The buzzer will buzz on alert and the LCD will display the bed number of the bed patient needing attention. The RGB LED will determine the battery level of the device. Once a particular device receives an alert for a set amount of time without responding, the alert is resent to a different PDU. 


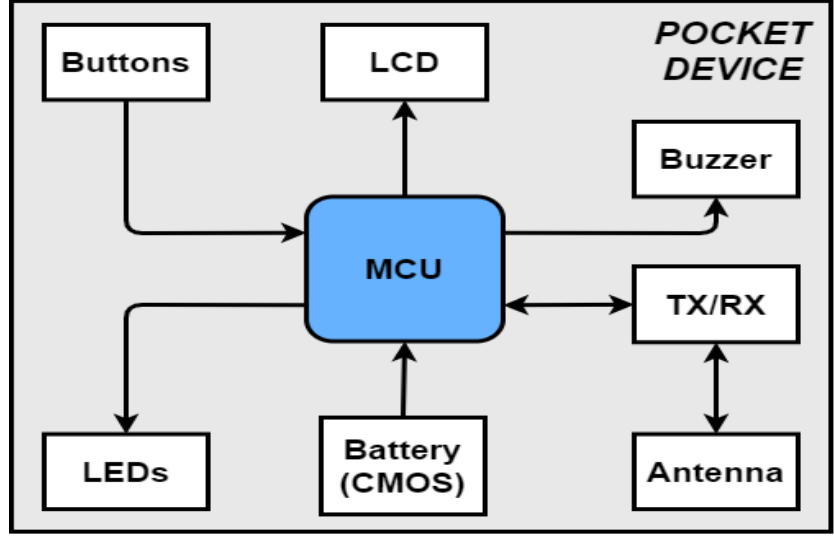

FIGURE 6 PDU Block Diagram

\section{PDU Workflow}

When the PDU is powered, the red LED turns on to indicate device readiness. As shown in figure 7, at start, the PDU continually awaits a signal from the BDU. If a signal is received from the BDU that a patient needs attention, the buzzer beeps to draw the attention of the nurse, and the LCD screen displays the patient bed number to the nurse or caretaker, so they know the exact bed to go to. The PDU will continue to buzz and display the bed number for a set amount of time $\boldsymbol{x}$. As the beep and display is going on, there is a condition that is being checked. If the alert disable button from the BDU has been pushed, then an external interrupt is received by the PDU, and the cycle ends, and the beeping and display are stopped. But if no such signal is received, which means that no nurse has attended to the patient, the beep continues. As the alert is on-going for a particular device, after the set time $\boldsymbol{x}$ has elapsed, the system triggers a different PDU. This continues till the alert disable button has been pushed and that cycle ends.

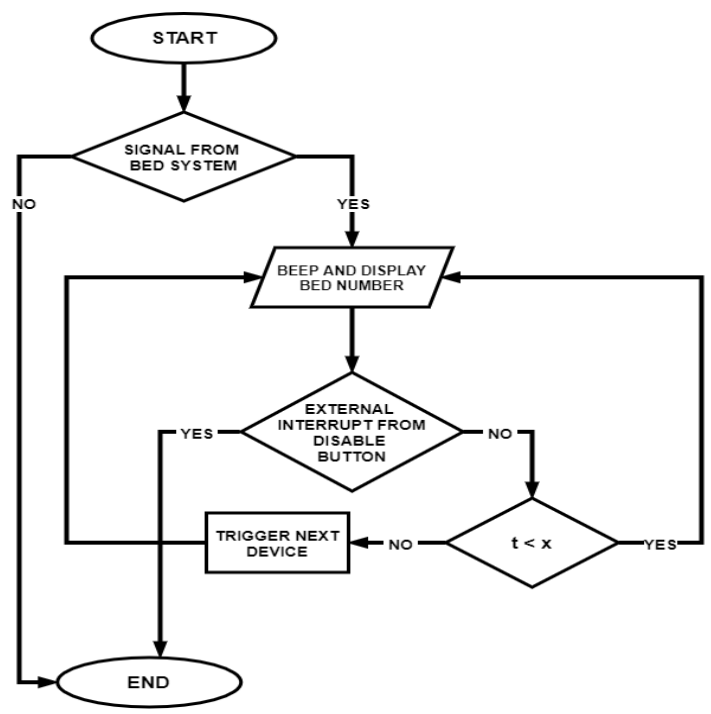

BeSoSys Database and Information Logging (DIL) The DIL which is the base station of the system is where the information logging amongst the PDU, BDU and sensors takes place. A desktop or laptop computer equipped with wireless communication was used as the base station. The main function of the base station was to keep a database of the alert trigger times and disable times among others. A software application or graphical user interface (GUI) as shown in figures 8 and 9 is used to access or interface with the database in the cloud.

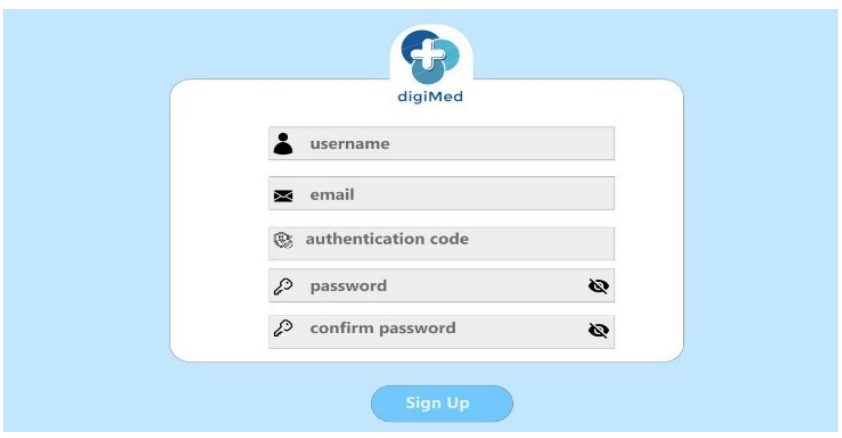

FIGURE 8 BeSoSys DIL Software Application Sign up

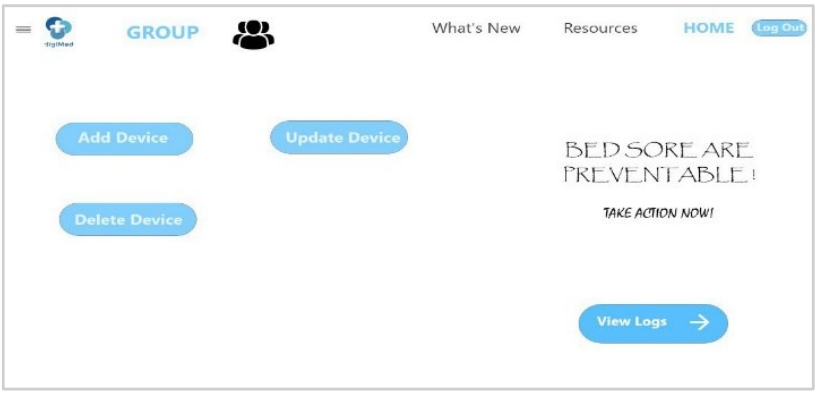

FIGURE 9 BeSoSys DIL Software Application Homepage

In the DIL, users, after gaining access can perform several functions aside checking the logs for the various BDUs. Users can add new BDUs and PDUs, as well as update (edit the information) and delete already existing BDUs and PDUs. Some information about the devices logged in the database are the names of the nurses or caretakers using the PDU, the names and bed numbers of patients using the BDU, among others. The database is also logged with alert trigger and alert disable time of a particular BDU, and the particular PDU that responded to alert. This logged database is mainly for management to keep account of nurses' activities and patient-treatment rate. Management can use this information to make major administrative decisions.

FIGURE 7 PDU Flow Chart 


\section{RESULTS}

A prototype of the Bedsore Easing System was set up as shown in FIGURE 10 and FIGURE 11. It consisted of the bed component unit equipped with a wi-fi enabled microcontroller, a pocket device unit and the base station or database. The bed component unit aside the wi-fi enabled microcontroller had a load cell sensor, temperature sensor, the alert disable button, and the relay-controlled pump. The pocket devices were represented by mobile phones, which served as the recipient of the alert. That is, two mobile phones with wi-fi capabilities were set up to serve as portable pocket devices. Using Blynk, an Internet-of-Things compatible application that enables communications between microcontrollers and smartphones, the alerts from the bed component system were received on the mobile devices, with the bed number displayed within as expected. FIGURE 12 and FIGURE 13 depict the alert messages.

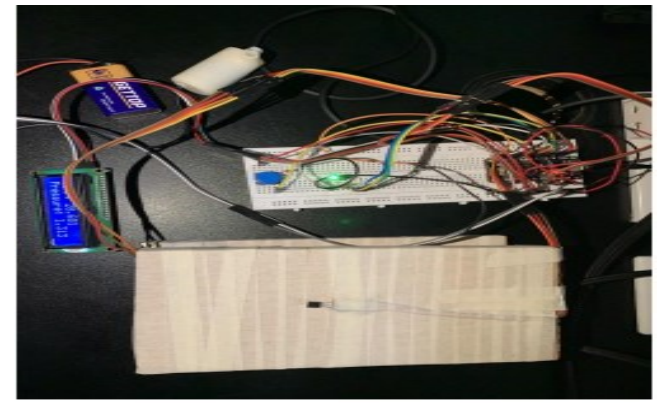

FIGURE 10 BeSoSys Prototype Setup I

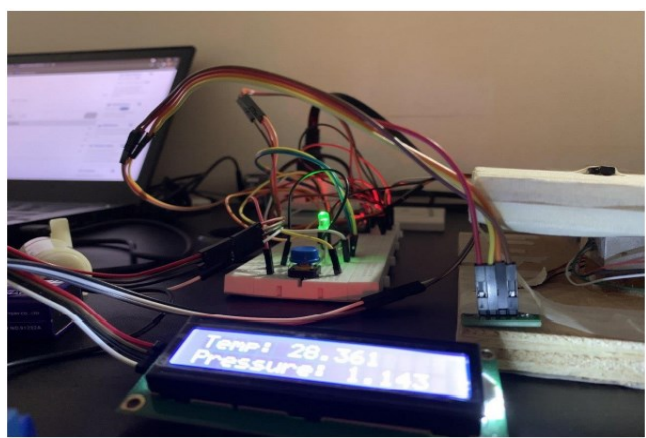

FIGURE 11 BeSoSys Prototype Setup II

A laptop with wi-fi capability was also set up as the base station to receive input into the database. The Adafruit API was utilized in this prototype. Here, the logs in the database were easily accessible through the Adafruit application. Anytime an alert is sent, it is logged into the database, and when the alert is disengaged or disabled, the time is also logged into the database. The logs in the database can be seen in figure 10 .

A series of tests were run on the prototype to evaluate the response of the system and its overall performance. In the test, sensor readings were monitored when a body is placed on 'the BDU, the response of the LEDs to changing values, and the response time of the alert, that is, how long it takes the alert to be triggered were all recorded. Close attention was paid to the triggering of the pump ie. how soon the relay kicks in; switching off or on and to the response of the system when the alert disable button is pushed.

\begin{tabular}{|c|c|}
\hline Created at & Value \\
\hline 2021/08/12 2:31:10PM & Alert Disabled \\
\hline 2021/08/12 2:30:18PM & Alert Sent \\
\hline 2021/08/12 2:28:52PM & Alert Disabled \\
\hline 2021/08/12 2:28:02PM & Alert Sent \\
\hline 2021/08/12 2:25:36PM & Alert Disabled \\
\hline 2021/08/12 2:25:17PM & Alert Sent \\
\hline 2021/08/12 2:24:44PM & Alert Disabled \\
\hline 2021/08/12 2:24:32PM & Alert Sent \\
\hline 2021/08/12 2:24:12PM & Alert Sent \\
\hline 2021/08/12 1:40:16PM & Alert Disabled \\
\hline 2021/08/12 1:39:34PM & Alert Sent \\
\hline 2021/08/12 1:39:19PM & Alert Sent \\
\hline 2021/08/12 1:17:09PM & Alert Sent \\
\hline $2021 / 08 / 12$ 1:16:29PM & Alert Disabled \\
\hline 2021/08/12 1:15:37PM & Alert Sent \\
\hline 2021/08/12 1:14:36PM & Alert Disabled \\
\hline 2021/08/12 1:14:15PM & Alert Sent \\
\hline
\end{tabular}

FIGURE 12 Received Alerts and Timestamp

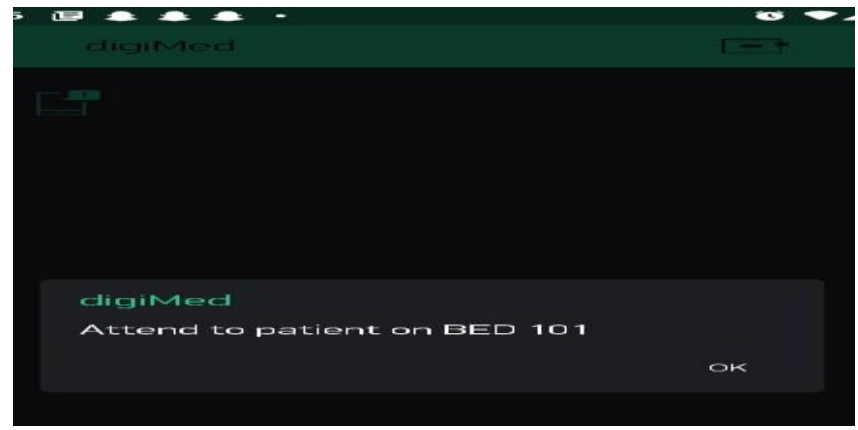

FIGURE 13 BeSoSys Alert Screen

TABLE 2 shows the log of alerts triggered, alert disabled and timestamps as well as, the temperature and pressure readings. The idle time is the time where pressure and temperature have not breached the set threshold, but the patient still needs to be moved. In other words, when a patient has been lying down in a fixed position for a certain amount of time, regardless of the pressure or temperature reading, the said patient needs to be massaged and turned or repositioned. This amount of time is the idle time., and the system triggers an alert when such time is reached. 
Table II

Pressure and temperature values at alert times

\begin{tabular}{|c|c|c|c|c|c|}
\hline \# & $\begin{array}{l}\text { Alert Sent } \\
\text { Time }\end{array}$ & $\begin{array}{l}\text { Alert Disable } \\
\text { Time }\end{array}$ & Idle Time & Pressure & $\begin{array}{l}\text { TEMP } \\
\left({ }^{0} \mathrm{C}\right)\end{array}$ \\
\hline 1 & 12:41:13PM & $12: 41: 29 \mathrm{PM}$ & $\checkmark$ & 672.50 & 32.56 \\
\hline 2 & $1: 10: 40 \mathrm{PM}$ & $1: 11: 28 \mathrm{PM}$ & $\checkmark$ & 883.80 & 34.20 \\
\hline 3 & $1: 12: 08 \mathrm{PM}$ & $1: 12: 51 \mathrm{PM}$ & $\checkmark$ & 505.60 & 34.70 \\
\hline 4 & $1: 14: 15 \mathrm{PM}$ & 1:14:36PM & & 1706.00 & 42.20 \\
\hline 5 & $1: 15: 37 \mathrm{PM}$ & 1:16:29PM & $\checkmark$ & 545.62 & 42.54 \\
\hline 6 & 1:39:34PM & $1: 40: 16 \mathrm{PM}$ & & 1370.70 & 44.83 \\
\hline 7 & $2: 24: 12 \mathrm{PM}$ & $2: 24: 44 \mathrm{PM}$ & & 1157.50 & 42.18 \\
\hline 8 & $2: 25: 17 \mathrm{PM}$ & $2: 25: 36 \mathrm{PM}$ & & 1200.70 & 36.50 \\
\hline 9 & 2:28:02PM & $2: 28: 52 \mathrm{PM}$ & & 1061.30 & 35.77 \\
\hline 10 & $2: 30: 18 \mathrm{PM}$ & $2: 31: 10 \mathrm{PM}$ & $\checkmark$ & 136.05 & 35.46 \\
\hline
\end{tabular}

In table 2, from the 'idle time' column, it was observed that $50 \%$ of the alerts were triggered by idle time (rows with the check sign), and the other $50 \%$ were by temperature and pressure threshold breach. The idle time limit was set to 20 seconds, and the temperature and pressure thresholds were set to $32^{\circ} \mathrm{C}$ and $1,000 \mathrm{~N}$ respectively. The threshold values will vary based on a range of masses by the patients. When both temperature and pressure have not reached the set threshold, no alert is sent until the idle time has elapsed. Likewise, when temperature and pressure readings have both breached the set thresholds, a wait time of 5 seconds is initiated. Within the 5 seconds, if readings do not drop below the threshold, the alert is sent.

\section{DISCUSSIONS}

The various blocks or units of the system worked as expected. The recorded values showed that the expected functionality of the system was achieved. Two mobile devices were used to test the functionality of alerts being sent continuously to a particular pocket device till the allocated time is reached, and another device being triggered. When the notification from a particular device is ignored for about 20 seconds, the next device is triggered. The alerts were sent back and forth till the alert disable button on the bed component unit is pushed. It was observed that, when the connection to the database is severed, the whole system restarts to reestablish connection. This restart is not intended or desirable, but the restart time is short and hence minimal disruption was experienced. Also, it was noticed that when the Wi-Fi connection is not strong enough, it takes a while for the database to be updated.
Therefore, for optimal database update time, the wi-fi connection to the systems must be very strong.

In situation where alert triggering failed, it was found out that it was due to the weakness of the wifi reception. The system is therefore strongly dependent on the wifi connectivity in the environment.

Unlike some of the related works, the BeSoSys can be deployed on a large scale in the country's hospitals. BeSoSys is relatively cost effective compared with other implementations due to the use of fewer components and materials. The modular nature of the units allows the integration into already existing system, hence eliminating the need for replacements of existing beds. The proposed system proved to be more beneficial because it deals with the prevention of bedsores as opposed to some related works that are geared towards the identification of the stage and assistance in treatment and decision making.

Related works were found to have only one sensor: either the temperature or pressure sensor. BeSoSys on the other hand has integrated sensors (temperature, weight sensor or load sensor) as well as the alert signals making it more robust and efficient.

\section{CONCLUSION}

This project was commenced to solve the problem of the occurrence of bedsores in hospitals and care homes in Ghana. Some of the causes of bedsores were identified, and some factors in our hospitals that do not help the situation also noted. Direct causes of bedsores are the increase in pressure and temperature on the bony prominences of the body, hence the patients need the ultimatum of having these pressures redistributed along their bodies in the form of repositioning. 
This paper proposed, implemented, and tested a system to monitor pressure and temperature readings to ease the occurrence of bedsores. With this system, nurses can easily be alerted when patients need their attention. And patients are given some form of relief as they wait shortly to be attended to by the nurses. The BeSoSys solution proves effective in curbing or reducing the occurrence of bed sores. It can be used in hospitals, care homes or elderly homes, or even in private homes. This project contributes to Sustainable Development Goal (SDG) No. 3; "TO ENSURE HEALTHY LIVES AND PROMOTE WELL-BEING FOR ALL AT ALL AGES ACROSS ALL RACES". Future works on the Bedsore Easing System (BeSoSys) would look at the comfortability of the patient by improving the BDU such that when the inflationdeflation mechanism is triggered, the bed pad would be aired appropriately; either warm or cold. The DIL would be expanded to additionally log statistical data and identification of nurses or caretakers who attended to patients. The PDU would be design in such a way to provide nurses or caretakers with some configuration options.

\section{REFERENCES}

[1] Amanda Jönsson and Erica Engman, "Pressure Ulcer Prevention In Ghana", THE RED CROSS UNIVERSITY COLLEGE, Mar 22 $2^{\text {nd }}$, 2011 [online]. Available: https:/www.divaportal.org/smash/get/diva2:414949/FULLTEXT01.pdf

[2] Francesco Orciuoli, Francesco J. Orciuoli, Angela Peduto, 'A Mobile Clinical DSS based on Augmented Reality and Deep Learning for the home cares of patients afflicted by bedsores', Procedia Computer Science, vol. 175 , pp. 181-188, 2020. Accessed on: $7^{\text {th }}$ October, 2021) [online]. ISSN 1877-0509

[3] A. Abdelmoghith, R. Shaaban, Z. Alsheghri and L. Ismail, "IoTBased Healthcare Monitoring System: Bedsores Prevention,"2020 Fourth World Conference on Smart Trends in Systems, Security and Sustainability (WorldS4), London, UK, 2020, pp. 64-69, doi: 10.1109/WorldS450073.2020.9210319

[4] P. Nair, S. Mathur, R. Bhandare and G. Narayanan, "Bed sore Prevention using Pneumatic controls," 2020 IEEE International Conference on Electronics, Computing and Communication Technologies (CONECCT), Bangalore, India, 2020, pp. 1-5, doi: 10.1109/CONECCT50063.2020.9198410.

[5] Mattress for Preventing Bed Sores, by E Allan Blair (1975, July 8), patent no. US3893198 [online]. Available: https://patents.google.com/patent/US3893198A/en

[6] Patient Under Sheet for Preventing Bed Sores, by Nathan Mayer (1986, September 30), patent no. US4614000A [online]. Available: https://patents.google.com/patent/US4614000A/en

[7] Fluid-Type Support Structure for Simulating Flotation-Type Support, by James D. Weinstein (1971, April 13), patent no. US3574873A [online]. Available: https://patents.google.com/patent/US3574873A/en

[8] Monitoring System for Pressure Sore Prevention, by David Mravyan, Milos Popoviv and Michael Mravyan (2015, October 6), patent no. US9149211B2 [online]. Available: https://patents.google.com/patent/US9149211B2/en

[9] M. Yip, D. D. He, E. Winokur, A. G. Balderrama, R. Sheridan and H. Ma, "A flexible pressure monitoring system for pressure ulcer prevention," 2009 Annual International Conference of the IEEE Engineering in Medicine and Biology Society, Minneapolis, MN, USA, 2009, pp. 1212-1215, doi: 10.1109/IEMBS.2009.5333964.

[10] M. Kosaka and M. Takahashi, "Stage identification using electromagnetic waves for noncontact bed sores detection system," 2019 International Symposium on Antennas and Propagation (ISAP), Xi'an, China, 2019, pp. 1-3.
[11] Pressure ulcer condition sensing and monitoring, by Giovani M. Ortega George B. Schwabe IvJohn A. Sabolich (2000, January 4), patent no. WO2001000089A1[online]. Available: https://patents.google.com/patent/WO2001000089A1/en?oq=WO2 001000089A1

[12] Blanching response pressure sore detector apparatus and method, by Geoffrey Taylor (2004, March 18), patent no. US20040054303AI [online]. Available: https://patents.google.com/patent/US20040054303A1/en

[13] Smart Bed, by Evelyn Torres (2017, September 28), patent no. WO2017165544A1 [online]. Available: https://patents.google.com/patent/WO2017165544A1/en

[14] Adaptable surface for use in beds and chairs to reduce occurrence of pressure ulcers, by George Papaioannou (2014, June 17), patent no. US20150128352A1 [online]. Available: https://patents.google.com/patent/US8752222

[15] A cot to prevent and treat bedsores, by Kalyanaraman S. R. (2014 June 4), patent no. WO2015015510A3 [online]. Available https://patents.google.com/patent/WO2015015510A3/en?oq=WO2 $\underline{015015510 \mathrm{~A} 3}$

[16] G. Fiedler, G. Papaioannou, C. Mitrogiannis, G. Nianios and T. Kyprianou, "Development of a new bed system with improved decubitus prophylaxis for bed-ridden patients," 2009 9th International Conference on Information Technology and Applications in Biomedicine, Larnaka, Cyprus, 2009, pp. 1-4, doi: 10.1109/ITAB.2009.5394379.

[17] Automatic patient turner, by Michael Ben-Levi (2006, October 21), patent no. WO2004089270A1 [online]. Available: https://patents.google.com/patent/WO2004089270A1/en

[18] Cushion for decubitus ulcers, by Samuel Pertchik (1979, March 17), patent no. US4255824A [online]. Available: https://patents.google.com/patent/US4255824

[19] Bed, by John Rees (2004, November 4), patent no. US20040216235A1 [online]. Available: https://patents.google.com/patent/US20040216235A1/en?oq=US20 040216235A1

[20] K. S Jaichandar, Mohan Rajesh Elara, Adrian Chua, Sampath Kumar, "A Semi-Autonomous Control and Monitoring System for Bed Sores Prevention", i-CREATe '07: Proceedings of the 1st international convention on Rehabilitation engineering \& assistive technology: in conjunction with 1st Tan Tock Seng Hospital Neurorehabilitation Meeting, 2007, pp. 245-248.

[21] K. S. Jaichandar and E. A. M. García, "Intelli-sense bed patient movement sensing and anti-sweating system for bed sore prevention in a clinical environment," 2011 8th International Conference on Information, Communications \& Signal Processing, Singapore, 2011, pp. 1-5, doi: 10.1109/ICICS.2011.6174255.

[22] R. Yousefi et al., "A smart bed platform for monitoring \& Ulcer prevention," 2011 4th International Conference on Biomedical Engineering and Informatics (BMEI), Shanghai, China, 2011, pp. 1362-1366, doi: 10.1109/BMEI.2011.6098589.

[23] Method and system for determining whether a patient has moved or been moved sufficiently to prevent patient bedsores, by Neil Kusens (2016, October 27), patent no. US20160314258A1 [online]. Available:

https://patents.google.com/patent/US20160314258A1/en 